\title{
Insulin resistance by homeostasis model assessment in HIV-infected patients on highly active antiretroviral therapy: cross-sectional study
}

Miguel A. Guillen ${ }^{1}$, Fernando A. Mejia ${ }^{2}$, Jaime Villena ${ }^{3}$, Christie G. Turin ${ }^{1 *}$, Cesar P. Carcamo ${ }^{4}$ and Ray Ticse ${ }^{1,3}$

\begin{abstract}
Background: The highly active antiretroviral therapy (HAART) has altered the course of HIV infection, transforming it from a fatal illness to a chronic condition, reducing morbidity and mortality. However, this therapy has led to an increased incidence of metabolic problems such as insulin resistance, dyslipidemia, lipodystrophy and impaired glucose metabolism.

The objectives of this study are to determine the prevalence of insulin resistance (IR) in a cohort of human immunodeficiency virus (HIV)-infected patients on highly active antiretroviral therapy (HAART) and to investigate the potentially associated factors.
\end{abstract}

Methods: We conducted a cross-sectional study including 219 adult patients with HIV on HAART. IR was determined through the homeostasis model assessment (HOMA-IR) mathematical model, using fasting plasma glucose (FPG) and insulin. Bivariate and multivariate analyses were performed to assess the association between demographic information, clinical characteristics and laboratory results, and IR.

Results: 75 (34.2 \%) [95 \% confidence interval (CI) 28.9-40.9] HIV-patients on HAART showed IR. 61 (81 \%) of these patients were on HAART for more than one year, which was mainly composed by non-protease inhibitors drugs (88 \%). Metabolic syndrome (MS) was found in 59 (26.9\%) subjects. In the multivariate analysis, the factors associated with IR were age $\geq 46$ years (Prevalence ratio $=2.767,95 \% \mathrm{Cl} 1.325$ to 5.780 ) and greater body mass index (BMI) (Prevalence ratio $=1.148,95 \% \mathrm{Cl} 1.054$ to 1.250$)$.

Conclusions: The prevalence of IR was $34.2 \%$. Factors associated with IR were age and BMI. We did not find any significant association between IR and protease inhibitors (PI), which may be explained by the small number of patients using $\mathrm{PI}$ as part of their HAART regimen included in our study.

Keywords: Insulin resistance, HIV, HAART, HOMA, Metabolic syndrome

\section{Background}

World Health Organization and UNAIDS report about 39.5 million HIV-infected people worldwide and about 2 million people in Latin America. In 2009, around 70,000 people were estimated to be infected in Peru. The advent of HAART has altered the course of HIV infection, transforming it from a fatal illness to a chronic condition and thereby reducing morbidity and mortality [1]. However, antiretroviral therapy has also led to an increased

\footnotetext{
* Correspondence: christie.turin@upch.pe

'Department of Medicine, Universidad Peruana Cayetano Heredia, Avenue

Honorio Delgado 430, San Martin de Porres, Lima, Peru

Full list of author information is available at the end of the article
}

incidence of metabolic problems such as IR, dyslipidemia, lipodystrophy and impaired glucose metabolism [2].

HAART comprises a combination of at least three active antiretroviral drugs against the virus which belong to different classes of drugs with different sites of action. The preferred initial regimen is the combination of two nucleoside reverse transcriptase inhibitors with a nonnucleoside reverse transcriptase inhibitor or with a PI. The adverse effects of these medications include metabolic disorders. The antiretroviral drugs most frequently associated with the development of lipodystrophy and IR are the PIs such as lopinavir, ritonavir and nelfinavir [3]. 
IR, impaired glucose tolerance (IGT) and type 2 diabetes mellitus (T2DM) are part of a plurimetabolic syndrome associated with HAART, thus, the detection of this syndrome should be systematic. Guidelines recommend testing FPG at the time of HIV diagnosis, before initiating HAART, and every 6-12 months during treatment [4]. Also, performing an oral glucose tolerance test when a patient presents with abnormal fasting glucose is recommended [5]. This strategy allows the detection of most cases of T2DM; however, it misses some cases of IR. An early diagnosis of IR could allow for lifestyle modification in order to prevent progression to T2DM.

The HOMA mathematical model is a clinical and epidemiological tool used to estimate IR based on plasma levels of fasting glucose and insulin [6]. In order to investigate the prevalence of IR and the potentially implicated factors, we conducted a cross-sectional study in a cohort of Peruvian HIV-patients on HAART using the HOMA-IR. Moreover, we described the prevalence of MS according to the criteria proposed by The National Cholesterol Education Program's Adult Treatment Panel III report [7].

\section{Methods}

\section{Ethics statement}

The study was approved by the Institutional Review Board of the Universidad Peruana Cayetano Heredia and of the Hospital Nacional Cayetano Heredia. All the patients gave written informed consent to participate. Authors take complete responsibility for the integrity of the data and the accuracy of the data analysis.

\section{Study description}

A cross-sectional study of adult patients with HIV infection on HAART was carried out between June and October 2012 at the Institute of Tropical Medicine "Alexander von Humboldt", in the Hospital Nacional Cayetano Heredia in Lima, Peru.

Patients recruited were adults over 18 years of age diagnosed with HIV infection on HAART. We excluded patients with a known history of carbohydrate metabolism disorders (IGT, T2DM), diseases that alter insulin sensitivity (Cushing syndrome, Acromegaly, Polycystic ovary syndrome), use of corticosteroids, and pregnancy.

We obtained clinical records that included the following variables: age, gender, family history of diabetes in a first degree relative, smoking, blood pressure, weight, height, BMI, waist circumference, regimen and duration of HAART.

We obtained a fasting serum sample to measure levels of glucose, insulin, and lipids. Insulin level determination was performed using the immunoradiometric assay based on the separation of antibody-coated tube (INSIrma DIAsource-Belgium). This method has a detection limit, defined as the concentration resulting in two standard deviations above the average link of the zero calibrator, $1 \mathrm{uIU} / \mathrm{mL}$. The coefficient of variation intra-assay and inter-assay were $1.5 \%$ and $6.5 \%$ respectively.

Blood glucose was measured by the glucose oxidase method. Hyperglycemia was considered as a fasting glucose value $\geq 100 \mathrm{mg} / \mathrm{dL}$. Total cholesterol, high-density lipoprotein cholesterol (HDL-C), and triglycerides were determined by enzymatic method. Low-density lipoprotein cholesterol (LDL-C) was calculated according to the Friedewald formula.

The presence of IR was determined by the HOMA mathematical model using the following formula: [Insulin $(\mu \mathrm{U} / \mathrm{ml} \times$ glucose $(\mathrm{mmol} / \mathrm{L}) / 22.5]$. We defined IR as a HOMA-IR value $\geq 2.1$. This cutoff point was determined in a previous study conducted at the Hospital Nacional Cayetano Heredia in subjects with normal glucose tolerance tests [8].

\section{Statistical analyses}

Continuous variables were summarized using means and standard deviations, and comparisons between groups with and without IR were made using the Student's $t$-test. Categorical variables were summarized by frequencies and percentages, and their association with the outcome variable (IR) was determined using Fisher's exact test. Exposure variables with a "p" value below 0.10 in the bivariate evaluation were tested in multivariate models using "Generalized Linear Models" with the backward stepwise method, removing variable with $p$ values over 0.05 . Prevalence ratios, with their corresponding confidence intervals, were calculated as measures of excess risk.

The analysis was performed with the statistical program Stata SE version 11 (College Station, TX).

\section{Results}

\section{Participant's characteristics}

In this study, the response rate was $100 \%$. The demographic information, family and social history of 219 subjects are presented in Table 1 . The mean age of the study population was $38.4 \pm 10.1$ years. Most of the participants were male $(67.1 \%), 23.3 \%$ had a first-degree family history of T2DM and $24.7 \%$ patients were smokers. Regarding the treatment, (76.3\%) subjects were on HAART over a year and the most commonly used regimen did not include a PI (90.9\%).

\section{Clinical characteristics and laboratory results}

The mean BMI was $24.5 \pm 3.6$. Most patients had a normal weight (55.3\%), $32.0 \%$ overweight, $8.2 \%$ obese and $4.6 \%$ underweight. The mean abdominal circumference in men and women was $88.8 \pm 9.0 \mathrm{~cm}$ and $87.1 \pm$ $10.3 \mathrm{~cm}$, respectively (Table 2 ). Laboratory results are shown in Table 3. 
Table 1 Comparison of general characteristics of HIV-infected patients on HAART with and without insulin resistance (IR)

\begin{tabular}{|c|c|c|c|c|c|}
\hline General characteristics $(n=219)$ & Total $(n=219)$ & No IR $(n=144)$ & $\mathrm{IR}(n=75)$ & $P R$ & $P$ \\
\hline Male, $n(\%)$ & $147(67.1)$ & $96(66.7)$ & $51(68.0)$ & 1.041 & 0.844 \\
\hline Age & & & & & 0.007 \\
\hline$\leq 35$ years, $n(\%)$ & $95(43.4)$ & $70(48.6)$ & $25(33.3)$ & 1.000 & Reference \\
\hline $36-45$ years, $n(\%)$ & $74(33.8)$ & $50(34.7)$ & $24(32.0)$ & 1.232 & 0.398 \\
\hline$\geq 46$ years, $n(\%)$ & $50(22.8)$ & $24(16.7)$ & $26(34.7)$ & 1.976 & 0.002 \\
\hline Hispanics, $n(\%)$ & $190(86.7)$ & $124(86.1)$ & $66(88.0)$ & 1.119 & 0.709 \\
\hline Family history of T2DM, $n$ (\%) & $51(23.3)$ & $34(23.6)$ & $17(22.7)$ & 0.965 & 0.877 \\
\hline Cigarrette smoker, $n$ (\%) & $54(24.7)$ & $40(27.8)$ & $14(18.7)$ & 0.701 & 0.186 \\
\hline$>1$ year on HAART, $n(\%)$ & $167(76.3)$ & $106(73.6)$ & $61(81.3)$ & 1.357 & 0.249 \\
\hline HAART regimen with $\mathrm{PI}, n(\%)$ & $20(9.1)$ & $11(7.6)$ & $9(12.0)$ & 1.357 & 0.235 \\
\hline
\end{tabular}

Abbreviations: HAART highly active antiretroviral therapy; IR insulin resistance; $P R$ prevalence ratio; $P$ I protease inhibitor; T2DM type 2 diabetes mellitus

Prevalence of insulin resistance and metabolic syndrome The prevalence of IR was $34.2 \%$ (95 \% CI 28.9 - 40.9). MS was found in $26.9 \%$ subjects and was more prevalent in the IR group $(44.0 \%$ vs $18.1 \%)(p<0.001)$. The most frequently components of MS were low HDL-C, hypertriglyceridemia, and hyperglycemia (Table 4).

Hyperglycemia was found in 103 (47 \%) subjects, 9 (4.1\%) of them had serum glucose $>125 \mathrm{mg} / \mathrm{dl} .8$ (3.7\%) patients had hypertension. The prevalence of hypertriglyceridemia and low HDL-C was $48.4 \%$ and $57.5 \%$ respectively (Table 4).

\section{Comparison between the groups with and without insulin resistance}

Subjects with IR were older, had higher BMI, and were more likely to have hyperglycemia, central obesity and diastolic hypertension. With regard to the lipid profile, although the patients with IR had higher triglycerides levels, no significant differences were found when the variable was categorized as hypertriglyceridemia. There were no differences in gender, family history of T2DM, cigarette smoking, duration of HAART, using PI and systolic blood pressure (SBP).

In multivariate analysis, the factors associated with IR were age $\geq 46$ years $(\mathrm{PR}=2.767,95 \% \mathrm{CI} 1.325$ to 5.780 ) and greater $\mathrm{BMI}(\mathrm{PR}=1.148,95 \% \mathrm{CI} 1.054$ to 1.250$)$ (Table 5).

\section{Discussion}

In our study, the prevalence of IR was $34 \%$, two times higher than that of the non-HIV-infected population? The reported prevalence rates of IR among HIV-patients on HAART are highly variable, ranging from $13 \%$ to $45.7 \%$ [9]. Because our study did not have a control group of patients without HIV infection, the HOMAIR's cutoff was 2.1, which was based on a previous study conducted at the Hospital Nacional Cayetano Heredia in subjects without HIV infection and with similar geographical and ethnic characteristics. This value corresponds to the $75^{\text {th }}$ percentile value determined by that

Table 2 Clinical characteristics of HIV-infected patients on HAART with and without insulin resistance (IR)

\begin{tabular}{|c|c|c|c|c|}
\hline Clinical characteristics & Total $(n=219)$ & No IR $(n=144)$ & $\mathbb{I R}(n=75)$ & $P$ \\
\hline $\mathrm{SBP}, \mathrm{mmHg}$ & $104.7 \pm 11.9$ & $103.6 \pm 11.4$ & $106.8 \pm 12.6$ & 0.060 \\
\hline $\mathrm{DBP}, \mathrm{mmHg}$ & $68.5 \pm 8.2$ & $67.5 \pm 7.8$ & $70.4 \pm 8.6$ & 0.013 \\
\hline Weight, Kg & $64.7 \pm 11.5$ & $63.0 \pm 11.6$ & $67.9 \pm 10.7$ & 0.003 \\
\hline $\mathrm{BMI}, \mathrm{Kg} / \mathrm{m}^{2}$ & $24.5 \pm 3.6$ & $23.8 \pm 3.6$ & $25.6 \pm 3.5$ & 0.001 \\
\hline BMl categories & & & & 0.001 \\
\hline Underweight, n (\%) & $10(4.6)$ & $9(6.3)$ & $1(1.3)$ & 0.535 \\
\hline Normal weight, $n(\%)$ & $121(55.3)$ & $91(63.2)$ & $30(40.0)$ & Reference \\
\hline Overweight, $n(\%)$ & $70(32.0)$ & $35(24.3)$ & $35(46.7)$ & 0.011 \\
\hline Obesity, n (\%) & $18(8.2)$ & $9(6.3)$ & $9(12.0)$ & $<0.001$ \\
\hline Abdominal circumf. (cm) & $88.3 \pm 9.5$ & $86.8 \pm 9.8$ & $91.1 \pm 8.2$ & 0.001 \\
\hline Male, $\mathrm{cm}$ & $88.8 \pm 9.0$ & $88.2 \pm 9.2$ & $90.1 \pm 8.5$ & 0.219 \\
\hline Female, $\mathrm{cm}$ & $87.1 \pm 10.3$ & $83.9 \pm 10.3$ & $93.3 \pm 7.2$ & $<0.001$ \\
\hline
\end{tabular}


Table 3 Laboratory results of HIV-infected patients on HAART with and without insulin resistance (IR)

\begin{tabular}{|c|c|c|c|c|}
\hline Laboratory results & Total $(n=219)$ & No IR $(n=144)$ & $\mathrm{IR}(n=75)$ & $P$ \\
\hline Triglycerides, mg/dL & $189.4 \pm 147.8$ & $172.5 \pm 120.6$ & $221.9 \pm 186.1$ & 0.019 \\
\hline $\mathrm{LDL}-\mathrm{C}, \mathrm{mg} / \mathrm{dL}$ & $114.5 \pm 50.4$ & $110.5 \pm 51.9$ & $122.3 \pm 46.8$ & 0.101 \\
\hline $\mathrm{HDL}-\mathrm{C}, \mathrm{mg} / \mathrm{dL}$ & $41.5 \pm 14.1$ & $42.1 \pm 14.4$ & $40.2 \pm 13.5$ & 0.336 \\
\hline $\mathrm{FPG}, \mathrm{mg} / \mathrm{dL}$ & $100.9 \pm 19.8$ & $97.4 \pm 11.8$ & $107.6 \pm 28.6$ & $<0.001$ \\
\hline HOMA index & $2.6 \pm 3.0$ & $1.2 \pm 0.5$ & $5.3 \pm 3.7$ & $<0.001$ \\
\hline Female & $2.6 \pm 2.9$ & $1.2 \pm 0.5$ & $5.5 \pm 3.6$ & $<0.001$ \\
\hline Male & $2.5 \pm 3.0$ & $1.1 \pm 0.5$ & $5.2 \pm 3.8$ & $<0.001$ \\
\hline
\end{tabular}

Abbreviations: FPG fasting plasma glucose, HDL-C high-density lipoprotein cholesterol, HOMA homeostasis model assessment, LDL-C low-densitylipoprotein cholesterol

study for subjects without HIV infection, normal OGTT and normal weight. It is higher than the cutoff point of a study made with Peruvian Andean adults living at 4100 $\mathrm{m}$ above sea level $(\mathrm{HOMA}=1.4)$ and lower than the value found for Peruvian metropolitan population living at sea level $(\mathrm{HOMA}=3.56)[10]$.

Through bivariate analysis, we found the following variables to be associated with IR: age, diastolic blood pressure, weight, BMI, abdominal circumference and FGP. All of these variables are components traditionally associated with the development of IR in the general population [11]. Our study did not find a significant association between IR and the use of PIs, in contrast to other reports which showed a clear association [12, 13], this may be explained by the small number of patients [20 (9 \%)] using PI as part of their HAART regimen included in our study. In addition, we found that 9 of the 20 patients on PI used atazanavir, which has not been associated with IR in published studies [14]. On the other hand, the prevalence of IR was not significantly higher among patients who were more than one year on HAART compared to those who were less time on treatment, suggesting that IR occurs early. However, our study does not allow us to assess if the IR worsens with the course of the HIV infection. To evaluate this correlation, it would be necessary to conduct a longitudinal study. The long-term effects of antiretroviral drugs are poorly understood. Jemsek JG et al. found that the alteration of insulin sensitivity in the early stages of antiretroviral therapy tends to normalize over time [15].

In the multivariate analysis, through a logistic regression model using the variables that were significant in the bivariate analysis, we found that patients older than 46 years have almost three times more risk of IR compared with younger subjects. Similarly, we found an increased risk of IR with higher BMI; for each unit increase in BMI, the risk of IR increased by $15 \%$. The prevalence of MS in our series was $27 \%$, similar to the prevalence reported in American and Latin American series in patients with HIV infection [16, 17], and higher than the prevalence found in the Peruvian adult population without HIV infection (22\%) [18]. With regard to the components of MS, in our study, similar to other studies of MS in HIV patients, dyslipidemia and hyperglycemia predominant followed by obesity and hypertension. Also, a high percentage of patients with MS had normal weight, which differs from previous reports about MS in the general population, where abdominal obesity and hypertension are the principal components [19].

We found an alarmingly high prevalence of hyperglycemia (47\%), higher than that reported in other studies of HIV patients on HAART (38 \%) [20], these results suggest that HIV treatment is an important factor in the development of IR and other metabolic disorders such as IGT and T2DM. Unfortunately, our study did not

Table 4 Comparison of metabolic syndrome and its components in HIV-infected patients on HAART with and without IR

\begin{tabular}{|c|c|c|c|c|c|}
\hline Metabolic syndrome's components & Total $(n=219)$ & No IR $(n=144)$ & $\mathrm{IR}(n=75)$ & PR & $P$ \\
\hline Metabolic Syndrome, $n(\%)$ & $59(26.9)$ & $26(18.1)$ & $33(44.0)$ & 2.131 & $<0.001$ \\
\hline Central Obesity, $n(\%)$ & $49(22.4)$ & $25(17.4)$ & $24(32.0)$ & 1.633 & 0.007 \\
\hline Hypertriglyceridemia, n (\%) & $106(48.4)$ & $66(45.8)$ & $40(53.3)$ & 1.218 & 0.297 \\
\hline Low HDL-C, $n(\%)$ & $126(57.5)$ & $81(56.3)$ & $45(60.0)$ & 1.107 & 0.600 \\
\hline Hyperglycemia, $n$ (\%) & $103(47.0)$ & $58(40.3)$ & $45(60.6)$ & 1.689 & 0.008 \\
\hline $100-125 \mathrm{~g} / \mathrm{dL}$ & $94(42.9)$ & 57 (39.6) & $37(49.3)$ & 1.86 & 0.038 \\
\hline$>125 \mathrm{~g} / \mathrm{dL}$ & $9(4.1)$ & $1(0.7)$ & $8(10.7)$ & 2.75 & 0.004 \\
\hline High Blood Pressure, $n(\%)$ & $8(3.7)$ & $4(2.8)$ & $4(5.3)$ & 1.486 & 0.258 \\
\hline
\end{tabular}


Table 5 Multivariate logistic regression analysis for IR in HIVinfected patients on HAART

\begin{tabular}{rllll}
\hline Factor & PR & $P$ & $95 \% \mathrm{Cl}$ & \\
\hline Age (years) & \multicolumn{5}{c}{0.014} \\
$\quad \leq 35$ & 1.000 & Reference & & \\
$36-45$ & 1.070 & 0.848 & 0.533 & 2.150 \\
$\quad \geq 46$ & 2.767 & 0.007 & 1.325 & 5.780 \\
BMl & 1.148 & 0.002 & 1.054 & 1.250 \\
\hline Abbreviations: & BMl body mass index & Cl confidence interval $P R$ prevalence ratio
\end{tabular}

perform oral glucose tolerance test so that there may be cases of T2DM undiagnosed.

The prevalence of hypertension was $3.7 \%$, lower than that found in a previous study (16\%) [21]. This low prevalence may be due to the lower age of the enrolled patients.

The study's limitations were the lack of a control group of HIV-uninfected subjects to define a more precise HOMA-IR's cutoff point and the clinical evaluation of lipodystrophy. In addition, variables such as CD4 count and viral load were omitted. These variables have been considered factors associated with IR in this specific population. Squillace $\mathrm{N}$ et al. found a significant association between a high CD4 count and IR [22]. However, El-Sadr WM et al. has shown an inverse relationship between CD4 count and IR [23]. These inconsistent associations, on regard the CD4 count, might reflect underlying immunological mechanisms that could affect the insulin sensitivity. Therefore, those two variables must be included in future studies as possible underlying factors. Finally an oral glucose tolerance test was not performed to diagnose T2DM.

\section{Conclusion}

In conclusion, this study shows a significant percentage of HIV-infected patients on HAART present IR. Factors associated with IR were age and BMI. Since these patients have a high frequency of dyslipidemia and tobacco consumption, the detection of IR and its risk factors will allow for the assessment of each patient's metabolic risk and will also promote addressing modifiable risk factors to prevent the development of T2DM and cardiovascular disease.

We did not find any significant association between IR and protease inhibitors, which may be explained by the small number of patients using PI as part of their HAART regimen included in our study.

Based on our results, we suggest following current guidelines for the use of antiretroviral therapy in HIV patients, which recommend performing laboratory tests, such as fasting glucose or OGTT, during follow-up. The use of HOMA-IR in these patients will require further longitudinal studies in order to demonstrate its usefulness in early predicting diabetes or IGT in this population.

\section{Abbreviations \\ BMI: Body mass index; Cl: Confidence interval; FPG: Fasting plasma glucose; HAART: Highly active antiretroviral therapy; HDL-C: High-density lipoprotein cholesterol; HIV: Human immunodeficiency virus; HOMA: Homeostasis model assessment; IGT: Impaired glucose tolerance; IR: Insulin resistance; LDL-C: Low- density lipoprotein cholesterol; MS: Metabolic syndrome; PI: Protease inhibitor; SBP: Systolic blood pressure; SD: Standard deviation; T2DM: Type 2 diabetes mellitus.}

\section{Competing interests}

The authors declare that they have no competing interests.

\section{Authors' contributions}

MAG, FAM, JV, CGT, CPC and RT have made substantial contributions to the conception and design, acquisition of data, analysis and interpretation of data. Also, all of them have been involved in the manuscript draft and all of them have approved the final version of the article.

\section{Author details}

${ }^{1}$ Department of Medicine, Universidad Peruana Cayetano Heredia, Avenue Honorio Delgado 430, San Martin de Porres, Lima, Peru. ²Department of Infectious Diseases, Hospital Nacional Cayetano Heredia, Lima, Peru. ${ }^{3}$ Department of Endocrinology, Hospital Nacional Cayetano Heredia, Lima, Peru. ${ }^{4}$ Department of Public Health, Administration and Social Sciences, Universidad Peruana Cayetano Heredia, Lima, Peru.

Received: 18 March 2015 Accepted: 22 May 2015

Published online: 30 May 2015

\section{References}

1. Antiretroviral Therapy Cohort Collaboration. Life expectancy of individuals on combination antiretroviral therapy in high-income countries: a collaborative analysis of 14 cohort studies. Lancet. 2008;372:293-9.

2. Triant VA, Lee H, Hadigan C, Grinspoon SK. Increased acute myocardial infarction rates and cardiovascular risk factors among patients with human immunodeficiency virus disease. J Clin Endocrinol Metab. 2007;92:2506-12.

3. Walli $R$, Herfort $O$, Michl GM, Demant $T$, Jager $H$, Dieterle $C$, et al. Treatment with protease inhibitors associated with peripheral insulin resistance and impaired oral glucose tolerance in HIV-1 infected patients. AIDS. 1998;12:F167-73.

4. Lundgren JD, Battegay M, Behrens G, De Wit S, Guaraldi G, Katlama C, et al European AIDS Clinical Society (EACS) guidelines on the prevention and management of metabolic diseases in HIV. HIV Med. 2008;9:72-81.

5. Schambelan M, Benson CA, Carr A, Currier JS, Dube MP, Gerber JG, et al. Management of metabolic complications associated with antiretroviral therapy for HIV-1 infection: recommendations of an International AIDS Society-USA panel. J Acquir Immune Defic Syndr. 2002;31:257-75.

6. Matthews DR, Hosker JP, Rudenski AS, Naylor BA, Treacher DF, Turner RC. Homeostasis model assessment: insulin resistance and beta-cell function from fasting plasma glucose and insulin concentrations in man. Diabetologia. 1985:28:412-9.

7. National Cholesterol Education Program (NCEP), Expert Panel on Detection, Evaluation, and Treatment of High Blood Cholesterol in Adults (Adult Treatment Panel III). Third Report of the National Cholesterol Education Program (NCEP) Expert Panel on Detection, Evaluation, and Treatment of High Blood Cholesterol in Adults (Adult Treatment Panel III) final report. Circulation. 2002;106:3143-421.

8. Villena J, Corigliano S, Guanira J. Determinant factors of the response insulinica in subjects with normal tests of oral tolerance to the glucose. Acta Medica Peruana. 2001;18:12-7.

9. Fuster M. Resistencia a la insulina en pacientes infectados por VIH en tratamiento antirretroviral. Thesis doctoral. Madrid, Spain; 2009. ISBN: 978-84693-1117-2. http://eprints.ucm.es/10228/1/T31490.pdf. Accessed 10 Jun 2012.

10. Baracco R, Mohanna S, Seclen S. Determination of insulin sensitivity through the HOMA method in adult populations living at the highlands and at sea level. In: Revista Medica Herediana. 2006; 17: 206-11. http://www.scielo.org.pe/ scielo.php?pid=S1018-130X2006000400004\&script=sci_abstract\&tIng=en. Accessed 15 Jun 2012. 
11. Haffner SM, Mykännen L, Festa A, Burke JP, Stern MP. Insulin-resistant prediabetic subjects have more atherogenic risk factors than insulinsensitive prediabetic subjects: implications for preventing coronary heart disease during the prediabetic state. Circulation. 2000;101:975-80.

12. Yarasheski KE, Tebas P, Sigmund C, Dagogo-Jack S, Bohrer A, Turk J, et al. Insulin resistance in HIV protease inhibitor-associated diabetes. J Acquir Immune Defic Syndr. 1999;21:209-16.

13. Justman JE, Benning L, Danoff A, Minkoff H, Levine A, Greenblatt RM, et al Protease inhibitor use and the incidence of diabetes mellitus in a large cohort of HIV-infected women. J Acquir Immune Defic Syndr. 2003;32:298-302.

14. Noor MA, Parker RA, O'Mara E, Grasela DM, Currie A, Hodder SL, et al. The effects of HIV protease inhibitors atazanavir and lopinavir/ritonavir on insulin sensitivity in HIV-seronegative healthy adults. AIDS. 2004;18:2137-44.

15. Jemsek JG, Arathoon E, Arlotti M, Perez C, Sosa N, Pokrovskiy V, et al. Body fat and other metabolic effects of atazanavir and efavirenz, each administered in combination with zidovudine plus lamivudine, in antiretroviral-naive HIV-infected patients. Clin Infect Dis. 2006:42:273-80.

16. Jacobson DL, Tang AM, Spiegelman D, Thomas AM, Skinner S, Gorbach SL, et al. Incidence of metabolic syndrome in a cohort of HIV-infected adults and prevalence relative to the US population (National Health and Nutrition Examination Survey). J Acquir Immune Defic Syndr. 2006;43:458-66.

17. Cahn P, Leite O, Rosales A, Cabello R, Alvarez CA, Seas C, et al. Metabolic profile and cardiovascular risk factors among Latin American HIV-infected patients receiving HAART. Braz J Infect Dis. 2010;14:158-66.

18. Baracco R, Mohanna S, Seclen S. A comparison of the prevalence of metabolic syndrome and its components in high and low altitude populations in Peru. Metab Syndr Relat Disord. 2007;5:55-62.

19. Nilsson PM, Engström G, Hedblad B. The metabolic syndrome and incidence of cardiovascular disease in non-diabetic subjects-a populationbased study comparing three different definitions. Diabet Med. 2007:24:464-72

20. Hejazi N, Rajikan R, Choong CL, Sahar S. Metabolic abnormalities in adult HIV infected population on antiretroviral medication in Malaysia: a crosssectional survey. BMC Public Health. 2013;13:758.

21. Berhane T, Yami A, Alemseged F, Yemane T, Hamza L, Kassim M, et al. Prevalence of lipodystrophy and metabolic syndrome among HIV positive individuals on Highly Active Anti-Retroviral treatment in Jimma, South West Ethiopia. Pan Afr Med J. 2012;13:43.

22. Squillace N, Zona S, Stentarelli C, Orlando G, Beghetto B, Nardini G, et al. Detectable HIV viral load is associated with metabolic syndrome. J Acquir Immune Defic Syndr. 2009;52:459-64.

23. El-Sadr WM, Mullin CM, Carr A, Gibert C, Rappoport C, Visnegarwala F, et al. Effects of HIV disease on lipid, glucose and insulin levels: results from a large antiretroviral-native cohort. HIV Med. 2005:6:114-21.

\section{Submit your next manuscript to BioMed Central and take full advantage of:}

- Convenient online submission

- Thorough peer review

- No space constraints or color figure charges

- Immediate publication on acceptance

- Inclusion in PubMed, CAS, Scopus and Google Scholar

- Research which is freely available for redistribution 